\title{
A Generalized Gas-Liquid Two-Phase Flow Analysis for Efficient Operation of Airlift Pump
}

Airlift pumps are finding increasing use where pump reliability and low maintenance are required, where corrosive, abrasive, or radioactive fluids must be handled and when a compressor is readily available. The objective of the present study is to evaluate the performance of a pump under predetermined operating conditions and to optimize the related parameters

The effects of design parameters viz. mass flow rate of air, immersion ratio, diameter of rising main etc. on the performance of airlift pump are presented. The larger diameter of rising main is found to be suitable for high flow rate of water. The injecting device used in the system has considerable effect on the performance of the pump. The paper is focused on the general mathematical expression to determine the effective diameter of nozzle applicable to air lift pump installations in the diameter range of $25.4 \mathrm{~mm} \leq d \leq 101.6 \mathrm{~mm}$. The various types of flows are visualized in the rising main of a pump and the corresponding airlift pump performance is analyzed. It is observed that the slug flow is more predominant for improving the performance of the pump.

Keywords: airlift pump, immersion ratio, two-phase flow, and injecting device

\section{Introduction}

The airlift Pump is a device for raising liquids or mixture of liquids (mostly water) and solids through a vertical pipe partially submerged in the liquid, by means of compressed air introduced into the pipe near the lower end. The compressed air is introduced through the injecting device located at the bottom of the air supply pipe. A rising main covers this assembly fixed in the well. A mixture of air and water is formed within the rising main leading to two-phase flow $(1,2)$. Since the density of air water mixture is much less than that of pure water, a very long column of air water mixture will be required to balance even a very short column of pure water. As such the flow of air water mixture will begin through the rising main and it will be issued continuously at the top of rising main so long as the supply of air is maintained. During early stages, the airlift pump was used for water lifting, later on, for lifting and transporting corrosive and radioactive liquids as well as for pumping crude oil $(3,4)$. Airlift pumps are very efficient devices for handling difficult pumping operations. Giot has pointed out their use for corrosive fluids, solid-liquid mixtures and under-sea operation (5).

Several investigators have studied the performance of airlift pumps: Among others are Pickert (6), Stenning A.H. and Martin C.B. (7) In terms of diameter of the rising main with concern to efficiency of pump an ambiguity was observed in the experimental results obtained by Pickert and Martin C.B.

The performance of the airlift pump depends upon several factors such as the rate of flow of air, the diameter of rising main, foot-piece design and submergence ratio. Nicklin (8) speculated that the efficiency might be high of small diameter tubes $(<20 \mathrm{~mm})$ and with low flow-rates (along with White and Beardmore and Zukoski) $(9,10)$. Stenning and Martin introduced the basic principles of the two-phase flows. The same plots of characteristics were produced in the study of Delano (11). Kouremenos and Staicos (12) proposed the experiments to obtain a perfect slug flow. A model to predict the height to which an airlift pump operating in the slug flow regime can lift a given volumetric flow rate of liquid, given the air flow rate and the pressure at the point of gas introduction, was published by Clark and Dabolt (13). De Cachard and Delhaye (14) used an approximation of the general Lockhart-Martinelli (15) correlation.

Paper accepted August, 2007. Technical Editor: Francisco R. Cunha.
An airlift pump is essentially a two-phase flow in a vertical pipe. Chisholm (16) provides a good starting point for basic definitions and flow patterns encountered in vertical pipe flows, but does not discuss design optimization. The basic flow patterns: bubbly, slug, churn and annular were presented by Collier and Thome (17). An optimum efficiency for a specific diameter and submergence ratio was found very close to the transition from slug to churn flow. (Hewitt and Roberts (18). Jayanti and Hewitt (19) concluded that the slug to churn transition is attributed to the flooding of the liquid film surrounding the bubble in slug flow. However, the exact definitions of each vary from author to author and flows are sometimes described as a combination of patterns. Several authors since the first studies of two-phase vertical flow in last century, have investigated the design of airlift (Stepanoff) (20). Though these studies deal with the optimization of airlift design, very few can be applied in practice.

The preliminary research work of G. K. Awari (21-22) includes the verification of the necessity for an injecting device for improving the performance of airlift pump. T.K.Theyyunini (23) reported an application of this fluid technology at nuclear chemical plant. The author had proposed an empirical formula to determine diameter of orifice plate through which air can be introduced into the foot piece. The equation is

$$
D 2=Q / 435 /(P 1-\mathrm{P} 2) P 2 / T 1 \text {. }
$$

This equation is based on the theoretical equation considering the work done and expansion of air in an isothermal process. This isothermal assumption cannot be justified for the work of compression and expansion of air and also, for orifices more losses occurs compared to nozzle because of the geometrical configuration.

Gad Hetersoni (5) reported that the design of the injection device has little influence on the efficiency of airlift pumps operating at large depths. G.J.Parkar (24) had focused on the effect of foot-piece (air jacket) with number of holes of the same diameter. The foot piece used in the study is an orifice plate and the conclusion is that the discharge characteristics of the airlift pump with the air-jacket foot piece were independent of the number and size of air injection holes. The foot piece proposed by Parkar is an integration of nozzle and orifice. This foot piece may follow different characteristics and an orifice of smaller diameter results in a higher pumping rate, quantity and it continues to increase with the decrease in the orifice area. The integrated foot piece proposed by 
Parkar is complicated to manufacture and the important parameter of submergence ratio was neglected in the study. Also the relationship between the diameter of injection device and diameter of rising main was not addressed in the above study.

All the studies depend on either an experimental data or empirical correlation factors pertaining to specific categories of practical application. Requirements of handling two-phase mixtures are increasing day-by-day and published test results are not focused on the effective nozzle diameter (injecting device) suitable for the diameter of the rising main. The present study is focused on the experimental analysis of the various parameters affecting the performance of airlift pump to predict the performance in relation to the gas flow rate and to get the efficient operation of the airlift pump. The study is leading to a more generalized mathematical function to determine the effective diameter of nozzle that will find its usefulness in the design of pump for its installation. An adiabatic process is justified by the compression and expansion of air and hence is considered in this analysis.

\section{Nomenclature}

$C_{a}$ - Concentration factor of Air

$C_{w}$ - Concentration factor of water.

$d$-Diameter of rising main

D- Nozzle diameter ( $\mathrm{mm}$ )

E-Effectiveness

$\mathrm{Fr}$-Froude number

g- Gravitational acceleration

$H / L$-Immersion ratio

H-Head developed

$L$ - length of rising main, $m$

$M_{a}$ - Mass flow rate of air

$M_{w}$ - Mass flow rate of water

$P$-Pressure of air

$Q-$ Flow rate, $\mathrm{l} / \mathrm{min}$

T1- temperature of air at inlet

$V_{a}-$ Superficial air velocity

$V_{m}-$ Mean velocity

$\varepsilon$-Immersion ratio

$\eta$ - Efficiency

\section{Subscripts}

\section{a- air}

$w$-water

1- Suction

2- Discharge

\section{Experimental Apparatus}

An airlift pump was designed and developed and was installed in the laboratory for experimental purposes. A schematic of the developed airlift pump with an injecting device at the bottom of the rising main is shown in Fig.1.

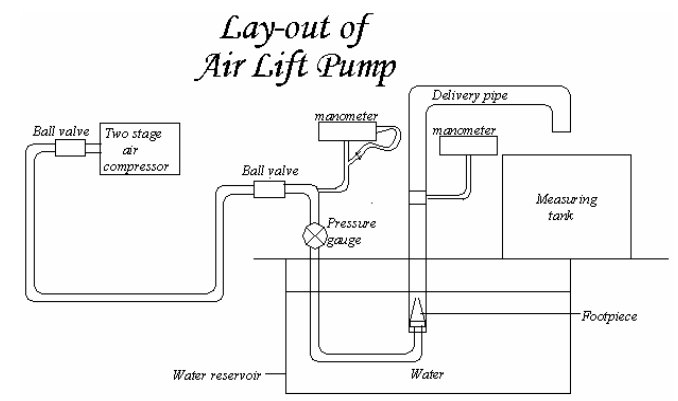

Figure1. Experimental apparatus.
The test rig consists of a vertical equipment with the facility to be interchangeable for replacing the diameter of rising main. The rising main is fixed vertically in the middle of a rectangular suction water reservoir of $0.84 \mathrm{~m} \mathrm{x} 1.21 \mathrm{~m}$ and $1 \mathrm{~m}$ high with its foot end $0.03 \mathrm{~m}$ above the bottom. The suction reservoir is equipped with a vertical scale water level indicator. The upper end of the rising main is connected to a metering water collection tank, where air is removed from the pumped mixture. Air is supplied to the air injection system from a two-stage air compressor. Through a 12.7$\mathrm{mm}$ diameter pipeline from the air reservoir, the air is allowed to flow to a pressure regulator, where the pressure is reduced to the working pressure. The air then passes through an injection device placed at the bottom of rising main. Air is metered and the mass flow rate is determined from the readings of the upstream pressure measured with a Pitot tube. All the holes in the injection devices used in the study are checked with a microscope after drilling and machining for accurate dimensions and roundness. Tests were conducted by varying the following; compressed air pressure, immersion ratio, and diameter of the injecting device. Initially, the necessity of the injecting device (nozzle) was verified experimentally and then the effect of nozzles with different diameters were studied. Measurements of the injected airflow rate, pumped water discharge, working head of a pump and submergence level of the riser in the suction water tank were performed. The water flow rate was measured with a collecting tank, by allowing the water to flow in a calibrated measuring tank of known size. The corresponding time required to collect the water was recorded. The measurements were carried out after achieving the stability of the system in terms of pressure of compressed air and the level of water in the tank. The readings were taken thrice to get accuracy of the results and normalized with the product of area of pipe and superficial water velocity indicating fractional velocity of air assuming air flowing alone in the same pipe or water flowing alone; both were fictitious. The temperature of the air was observed constant at $34^{\circ} \mathrm{C}$ and the uncertainty was $\pm 0.5^{\circ} \mathrm{C}$. The maximum equivalent uncertainty in the airflow rate was $\pm 3.5 \%$ and the uncertainty in the pump efficiency could be assumed as $\pm 4 \%$. Although both the water and air are travelling together in the same direction they usually travel at different speeds as a result of slippage between them. The local flow pattern and flow rates can fluctuate resulting in a fluctuating pressure drop. Two-phase friction is greater than single-phase friction for the same conduit dimensions and mass flow rate and definitely it will affect the overall performance of the system. The pump efficiency will decrease with the increase in head loss due to friction. The friction parameter $\mathrm{K}$ is taken as equal to $4 \mathrm{fL} / \mathrm{d}$. Two-phase flow adds many complications to the calculation of pressure drop, as the flow pattern will vary substantially from inlet to outlet. Therefore head loss due to friction is beyond the scope of this paper because of the difficulty of isolating and measuring these losses. Volumetric concentration of liquid as a fraction of the total volume of flow was calculated by the equations 1.1 and 1.2 and these were used for evaluating other influencing parameters of the pump.

$$
\mathrm{Cw}=\frac{V m(\sup \text { erficial })}{\operatorname{Vm}(\text { true })}
$$

and

$$
\mathrm{Ca}=\frac{V m(\sup \text { erficial })}{V m(\text { true })}
$$


and in two-phase flow, traditional dimensionless groups have very limited use in correlating data. There are several momentum transfer numbers most useful in characterizing particle suspension flows. Froude number is one of them given by equation 2

$$
F t=V a / \sqrt{g d}
$$

The length to diameter ratio of slugs varies greatly with flow rates, pipe diameter and fluid properties. If the diameter is very large the Froude number can always be large and slug flow, where the entire diameter bridged will not form. Immersion ratio $(\varepsilon)$ is defined as the ratio of submergence length of riser to the riser length. The efficiency of the pump was evaluated on the basis of the energy possessed by the air to operate the well. The input energy to the pump is the energy required for compressing the air and the output energy is the product of mass flow rate of water and head of mixture developed by the pump.

\section{Results and Discussions:}

The performance of the airlift pump depends upon several factors, such as the immersion ratio, airflow rate, diameter of rising main and the diameter of nozzle (injecting device). Two different models were compared (de Cachard (1996), Delano (1998)) with the experiments results so that an optimum performance for other parameters can be predicted. The results are shown if Fig.2. It is found that no single model works for the entire immersion ratios and diameters tested. Most of the models used were not built to predict and account for the transition from slug to churn flow. Delano's (1998) model seems to have noticeably similar behavior than other models. However, if the data for the other models had been extended into much higher flow rates, the same arched would be apparent for their plots in the figures as well. de Cachard and Delhaye (1996) model was also consistently the same slope as the experimental data up to the peak point, and not too far off of the values. The influencing parameters are studied experimentally and they are discussed below.

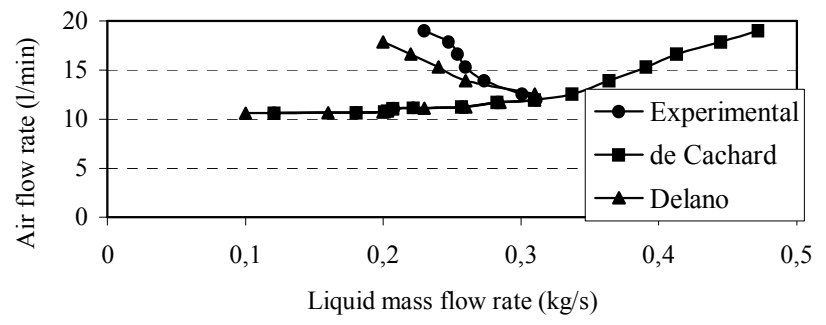

Figure 2. Air flow rate vc liquid mass flow rate.

\section{Discharge-Airflow Characteristics}

The effect of air pressure on discharge of a airlift pump for different diameters of a nozzle (injecting device) keeping the diameter of rising main and immersion ratio constant $(d=63.5 \mathrm{~mm}$ and $\varepsilon=1.21$ ), is shown in Fig.3. It is observed that the increase in pressure of air increases the discharge of a pump for all the diameters of nozzle and then it decreases. The optimum air pressure will differ from nozzle to nozzle. It is also clear that for constant air pressure the higher the nozzle diameter the higher is the discharge. Hence the nozzle having higher diameter is suitable for maximizing the discharge at any desired air pressure. The airlift pump works on the density difference principle where the density of mixture is varying and density of liquid remains constant. It is due to the fact that if the diameter of nozzle is large more quantity of pressurized air from the entrance will mix with the water resulting in a decrease of mixture density, which leads to gain in kinetic head. This ultimately results in the increase of discharge of water. The limiting value of compressed air pressure in this case is 3 bar for $63.5 \mathrm{~mm}$ diameter of rising main.

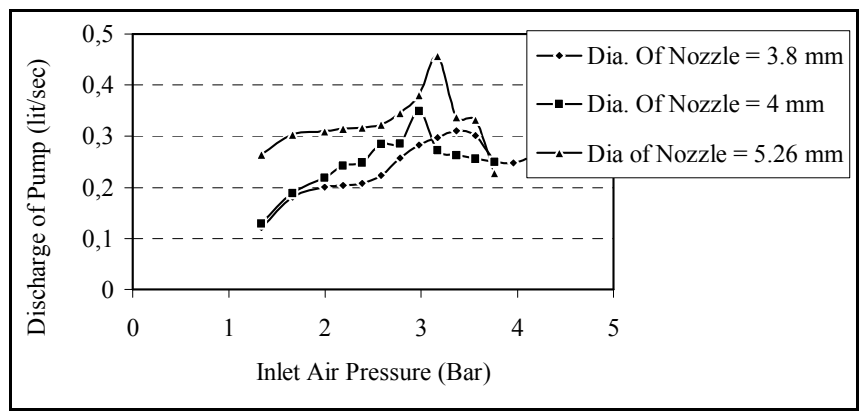

Figure 3. Discharge-Air flow characteristics for different nozzles.

\section{Utility of Injecting Device}

Initially the necessity of an injecting device is verified experimentally on $12.7 \mathrm{~mm}, 25.4 \mathrm{~mm}$ and 31.75-mm diameter rising main. Maximum discharge of a pump with narrow (12.7 $\mathrm{mm}$ dia.) and large diameter (25.4 $\mathrm{mm}$ dia. $31.75 \mathrm{~mm}$ dia.) rising main, without using nozzle was determined and it is tabulated below in the Table: B-1. With the use of nozzle no delivery of water was observed in case $12.7-\mathrm{mm}$ diameter rising main. Without nozzle it was not possible to lift water in large diameter of rising main. Hence it is concluded that for $12.7 \mathrm{~mm}$ diameter rising main there is no need of injection device and in large diameter rising main having diameters $\geq 25.4-\mathrm{mm}$ injection device is essential component in the system.

Table-B-1. Maximum discharge for different diameters of rising main.

\begin{tabular}{|c|c|c|c|}
\hline \multirow{2}{*}{$\begin{array}{c}\text { Length of pipe } \\
\text { under water } \\
(\mathrm{mm})\end{array}$} & $\begin{array}{c}\text { Maximum } \\
\text { Discharge }(1 / \mathrm{min}) \\
(12.7 \mathrm{~mm} \text { dia })\end{array}$ & \multicolumn{2}{|c|}{$\begin{array}{c}\text { Maximum Discharge } \\
(1 / \mathrm{min})\end{array}$} \\
\cline { 3 - 4 } & & $\begin{array}{c}25.4 \mathrm{~mm} \\
\text { dia }\end{array}$ & $\begin{array}{c}31.75 \mathrm{~mm} \\
\text { dia }\end{array}$ \\
\hline 990.6 & 1.98 & Nil & Nil \\
\hline 1066.8 & 2.28 & Nil & Nil \\
\hline 1143 & 2.586 & Nil & Nil \\
\hline 1219.2 & 3.0 & Nil & Nil \\
\hline
\end{tabular}

The raising of liquid was found to be mainly due to kinetic head. It was observed that in narrow diameter rising main the kinetic head is significant even without the nozzle and some quantity of water is lifted. The decrease in discharge without using an injecting device in case of large diameter rising main was observed to be about fifty percent, which may be compensated by operating the pump at higher immersion ratio. It is worth mentioning that the pump without injecting device is capable of lifting liquid with lower pressure of air in narrow diameter rising main. Depending upon the requirement, an economic and functional solution may justify the use of an injection device from energy considerations.

\section{Selection Criteria for Effective Nozzle Diameter}

The performance evaluation of air lift pump was carried out by conducting the tests with nozzles having different diameters viz. $5.26 \mathrm{~mm}, 4.0 \mathrm{~mm}, 3.80 \mathrm{~mm}$ and the different diameters of rising main (12.7 mm, $25.4 \mathrm{~mm}, 38.1 \mathrm{~mm}, 50.8 \mathrm{~mm}, 63.5 \mathrm{~mm})$. The effect of the variations in the nozzle diameter for constant diameter of rising main and immersion ratio on 
discharge, head and efficiency is summarized in table C-1. It is clear from the table $\mathrm{C}-1$ that for any constant diameter of rising main and immersion ratio, effect of the increasing the nozzle diameter is to improve the discharge and efficiency while there is decrease in the head developed by the pump.

The selection of optimum diameter of nozzle depends upon the diameter of rising main. The optimum diameter of nozzle can be evaluated from expression 3 .

$$
D=8.53 d^{2}-14.42 d+21.03 \text {. }
$$

Where $\mathrm{d}=$ diameter of rising main in inches and $\mathrm{D}=$ diameter of the nozzle in $\mathrm{mm}$. The algebraic equation based on the experimental analysis (Equation 3) is a generalized expression to find the optimum diameter of nozzle for the rising main diameters ranging from $25.4 \mathrm{~mm}$ to $101.6 \mathrm{~mm}$. In other practical applications one can go for the use of multiple rising mains of diameters $\leq 101.6$ $\mathrm{mm}$ instead of large size diameters $\geq 101.6 \mathrm{~mm}$. The separate injection device will be required in such cases and introducing the air at point of air injection separately in each rising main. The variation of predicted diameter of nozzle with respect to the diameter of rising main is shown in Fig.4.

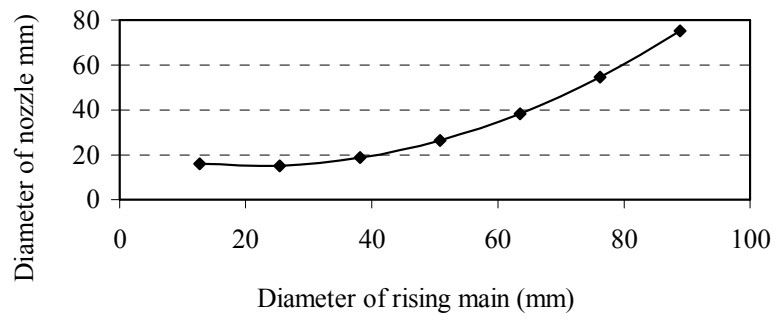

Figure4. Variation of diameter of nozzle with diameter of rising main.

\section{Effect of the Diameter of Rising Main}

The most significant geometric parameter for the efficient operation of airlift pump is the diameter of rising main. It has great effect on the efficiency of airlift pump. The variation of discharge with respect to diameter of rising main is shown in Fig.5.The crosssectional area required by air as it goes up increases linearly and the cross-sectional area required by water decreases. Thus the water velocity increases as it goes up. The difference between the mean air velocity in pipe and average velocity of water i.e. Relative air velocity determines the efficiency of pump. The higher the value of relative velocity the higher will be the air required from the compressor and therefore the efficiency will be lower. The relative air velocity is greater in narrow pipes as compared to that in larger diameter pipes. Increasing the relative air velocity means water particles are lagging the air and the discharge of the pump decreases. It is found that the discharge is negligible in narrow pipes. Increasing the pipe diameter reduces the relative air velocity and the discharge of the pump increases. Thus the efficiency is better for large diameter pipe as compared to narrow pipes. It is also evident from table $\mathrm{C}-1$ that the discharge and efficiency of pump for 63.5 $\mathrm{mm}$ diameter rising main is greater compared to $38.1 \mathrm{~mm}$ diameter rising main. The results obtained are in conformity with the results given by Stenning and Martin (1968) who has challenged the results of Pickert (1931) that narrow diameter pipe are better from an efficiency point of view.

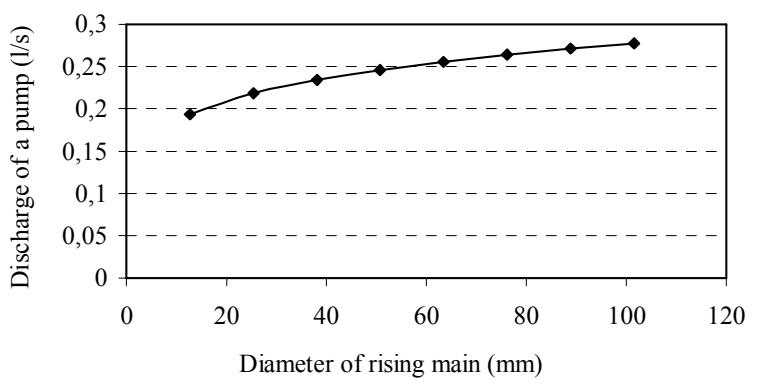

Figure5. Effect of diameter of rising main on discharge.

Table C-1. Comparison for different diameters of nozzle.

\begin{tabular}{|l|l|l|l|l|l|}
\hline $\mathrm{d}(\mathrm{mm})$ & $\varepsilon$ & $\mathrm{D}(\mathrm{mm})$ & Discharge $\mathrm{Q}_{\mathrm{w}}(\mathrm{l} / \mathrm{s})$ & $\mathrm{H}(\mathrm{m})$ & $\eta(\%)$ \\
\hline 38.1 & 0.54 & 5.26 & 0.28 & 1.05 & 8.46 \\
\hline 38.1 & 0.54 & 4.0 & 0.21 & 1.17 & 6.79 \\
\hline 38.1 & 0.54 & 3.80 & 0.19 & 1.35 & 5.71 \\
\hline 63.5 & 0.74 & 5.26 & 0.46 & 1.83 & 21.86 \\
\hline 63.5 & 0.74 & 4.0 & 0.13 & 2.48 & 11.45 \\
\hline 63.5 & 0.74 & 3.80 & 0.12 & 3.32 & 11.02 \\
\hline
\end{tabular}

\section{Immersion Ratio, Mass Flow Rates - Efficiency}

\section{Characteristics}

The variation of mass flow rates of water with respect to mass flow rate of air for different immersion ratio keeping diameter of rising main and nozzle constant, $($ Pipe Dia $=38.1 \mathrm{~mm}$, Nozzle Dia. $=$ $5.26 \mathrm{~mm}$ ) is shown in fig 6.1. The flow of water starts only when there is definite quantity of flow of air through the rising main of pump and the amount of air required is inversely proportional to immersion ratio. For the given mass flow rate of air, the amount of water lifted decreases with the decrease in immersion ratio. Small immersion ratio will lead to uneconomical working of pump as high velocity air mixes with water outside the rising main and bubbles formed escapes through the surface of water causing the loss of energy. For constant immersion ratio, the amount of water pumped increases with increase of air flow in the beginning and reaches its maximum and further increase of air flow rate do not alter the quantity of water lifted and fairly it is constant. Hence it is not justified to increase the flow of air beyond certain optimum value. In order to lift the maximum possible amount of water with minimum amount of air, the specific mass of air $\mathrm{m}_{\mathrm{asp}}=\left(\mathrm{m}_{\mathrm{a}} / \mathrm{m}_{\mathrm{w}}\right)$ should be as small as possible.

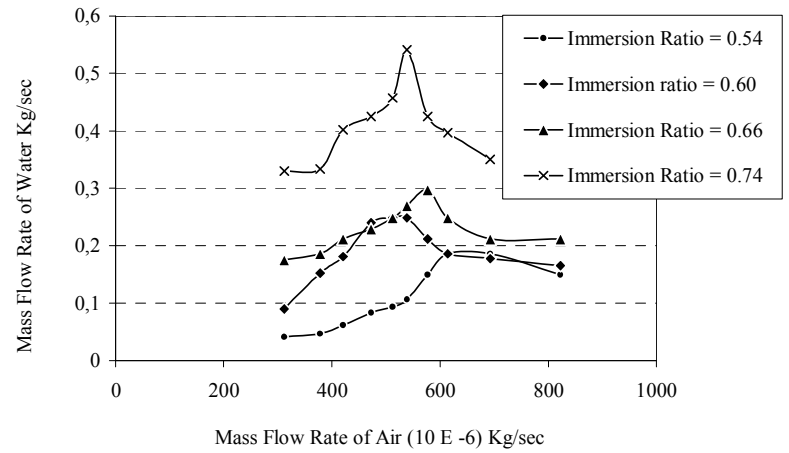

Figure 6.1. Comparison of mass flow rates with different immersion ratio.

The effect of immersion ratio on the efficiency of a pump with varying diameter of rising main $(63.5 \mathrm{~mm}$. and $38.1 \mathrm{~mm})$ is shown in Fig.6.2 and 6.3. It is found that with an increase in the immersion 
ratio the efficiency of pump increases for any diameter of rising main. It is also clear from the curves that the pump having higher diameters of rising main operates at higher efficiencies as discussed earlier in section D.

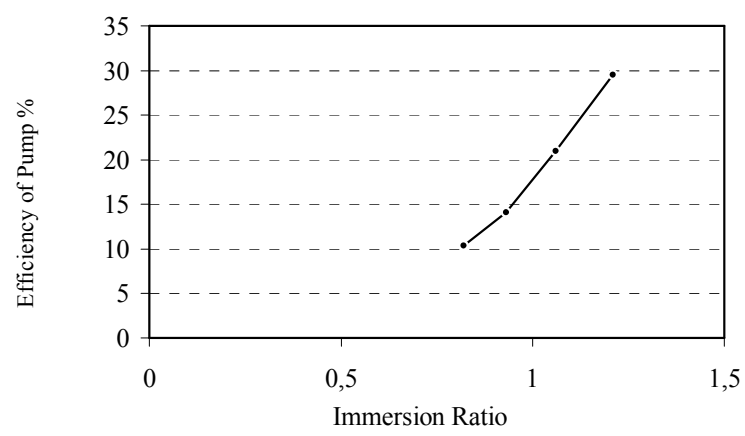

Figure 6.2. Effect of immersion ratio on the efficiency of pump ( $d=63.5$ $\mathrm{mm})$.

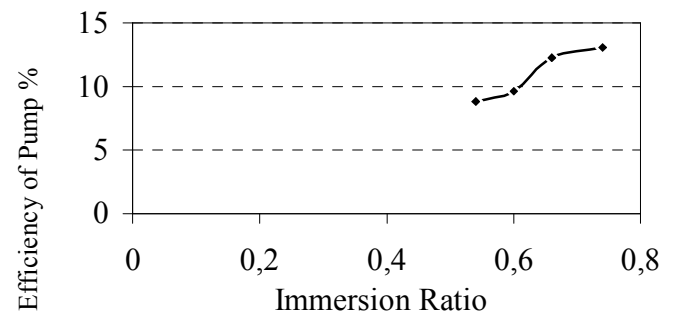

Figure 6.3. Effect of immersion ratio on the efficiency of pump (d $=38.1 \mathrm{~mm}$ ).

\section{Flow Visualization in the Rising Main:}

To visualize the two-phase flow inside the rising main a rising main of diameter $102 \mathrm{~mm}$ and length $1200 \mathrm{~mm}$ was developed in the laboratory. The transparent acrylic material was used for the rising main. The four types of two-phase flow viz. annular flow, Bubble flow, Churn Flow and Slug flow was observed in the rising main.

When the mass flow rate of air was $\leq 539.23 \times 10^{-6} \mathrm{~kg} / \mathrm{s}$, the velocity of bubble through water was also low and individual bubbles are in the form of rigid spheres and it can be clearly visualized at the tip of the nozzle. There is no coalescence of bubbles and they escape through the surface of the water. Such a flow of bubbles is called as bubbly flow. There is very little turbulence in the water column. At the same time the velocity of the bubbles also tends to increase. Some of the bubbles coalesce to form larger diameter bubbles, and the transition from bubbly flow to annular flow takes place. The turbulence in water column was increasing at higher rate and water surface fluctuates rapidly. Also the large bubbles alternate with liquid slugs that contain increasing amounts of small bubbles as flow rate increases. This is a characteristic of a slug flow as defined by Collier. The transition of slug to churn was observed when the airflow rate was in the range of $692.71 \times 10^{-6} \mathrm{~kg} / \mathrm{s}$ to $822.76 \times 10^{-6} \mathrm{~kg} / \mathrm{s}$. The photographs of the airwater flow at different air mass flow rates are captured with the high-resolution digital camera. These photographs are shown in the Fig. 7.1 to 7.4 .

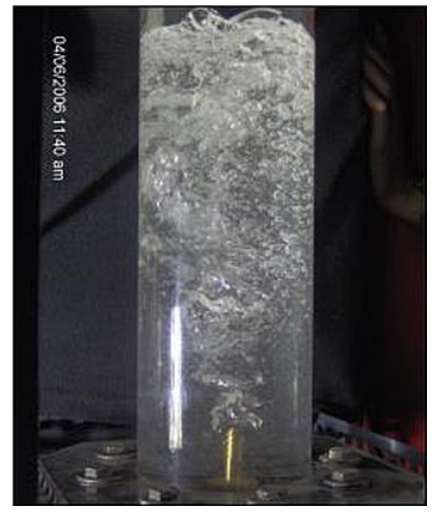

Figure 7.1. Annular flow

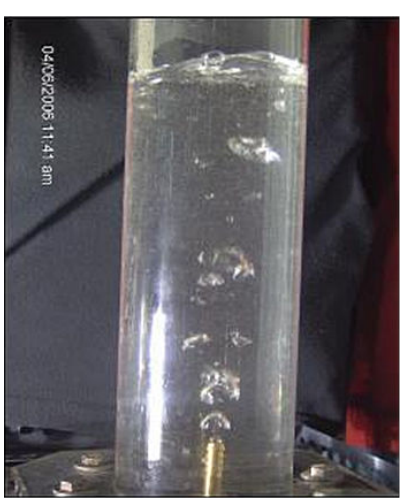

Figure 7.2. Bubble flow

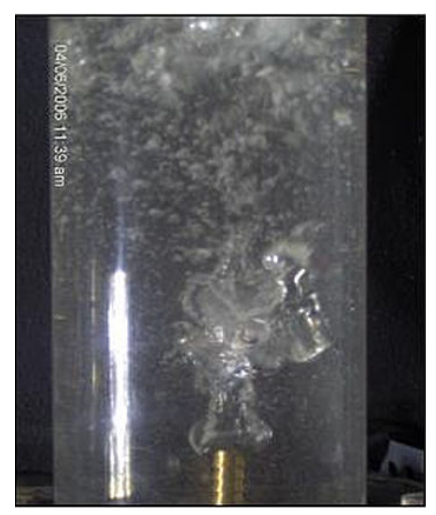

Figure 7.3. Churn flow

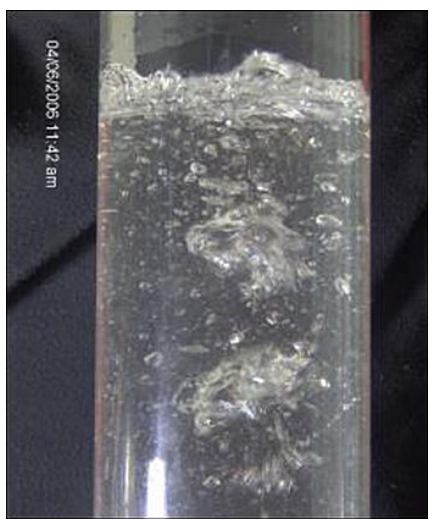

Figure 7.4. Slug rlow 
The location of transition from slug to churn flow, marked by a sharp change in slope, was at approximately the same liquid and airflow rates. From Fig. 2 and Fig. 8 it can be seen that there is an optimum efficiency to operate at for a specific diameter and submergence ratio. Operation at the peak of the curve would give the highest efficiency for a specific design scenario. It just so happens that the peak of the curve is very close to the transition from slug to churn flow. An example of this transition is seen in the sharp increase in slope in the experimental data of fig2. Comparing this with the maximum point in efficiency curve, it can be seen that the peak of the efficiency curve is very close to the transition from slug to churn flow, in fact it is right before the transition to churn, while once in the regime the efficiency decreases rapidly.

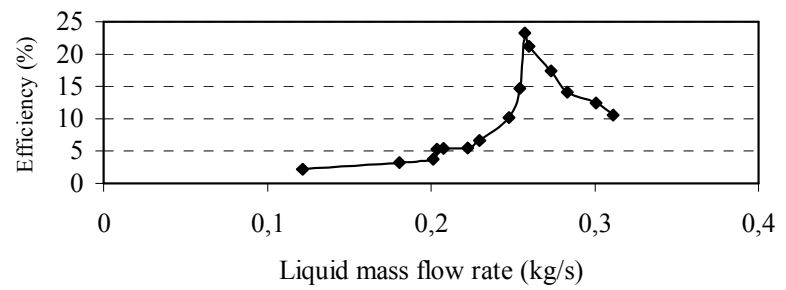

Figure 8. Experimental efficiency vs liquid mass flow rate.

Since the de Cachard and Delhaye (1996) model does not predict the transition, as an additional aide in finding the optimum operating conditions for any situation a transition criteria must be used as limiting factor.

\section{Conclusions}

An applied airlift model for air water flow has been developed based on experimental analysis of two-phase flow. This model has a very good performance. It has also simplified the performance analysis of airlift pump. Based on the results of experiments the following conclusions are drawn. The correlation available in the literature was found to fit our data.

1. The pressure of compressed air limits discharge of a pump. The pump should be operated below 3-bar pressure for 63.5 diameter of rising main.

2. It is desirable to introduce the air through a nozzle for larger diameter pipes $(\geq 25.4 \mathrm{~mm})$.

3. The optimum value of nozzle diameter is correlated with the diameter of rising main applicable in the range of: $25.4 \mathrm{~mm}$ $\leq \mathrm{d} \leq 101.6 \mathrm{~mm}$.

4. Larger diameter of rising main results in better efficiency of pump.

5. The efficiency of pump increases with increase in immersion ratio.

6. The maximum efficiency was observed during the slug flow.

\section{Acknowledgement}

The authors express their appreciation for the technical and financial support of this study from Shri Shrikant Patil, Director of Gajanan Shiskhan Sanstha. The support of Dr. P.D. Patil, Professor Mechanical Engineering department and Dr. H. M. Zha, Professor MBA department is gratefully acknowledged.

\section{References}

Govier and Aziz (1977): The flow of two-phase complex mixture in pipes, 324-337. Krieger Publication ltd., New York

Clement Kleinstreuer (2003): Two-Phase: Theory and Applications, 69128, Taylor and Francis, New york.

Vasandani V.P. (1992): Hydraulic Machines Theory and Applications, Academic press.

Perry R.H. Chemical Engineering Handbook, 5.40-5.48, McGraw Hill Book Company Sixth edition, New York

Giot, M. Edited by Hetersoni G. (1982): Three-phase flow, Handbook of Multiphase systems, Para 7.2 and 7.2.2.8 McGraw-Hill, New York.

Pickert F. (1932): The theory of air lift pump, Engineering, 34, 19-20.

Stenning A. H., Martin C.B. (1968): An analytical and experimental study of air lift pump performance, Journal Engng for Power Trans. ASME vol 90, 106-110.

Nicklin, D.J. (1963): The air-lift pump: Theory and optimization, Transaction of Institution of chemical engineers, 41: 29-39.

White E.T. and Beardmore R.H. (1962): The velocity of rise of single cylindrical air bubbles through liquids contained in vertical tubes. Chemical engineering Science, 17(5), 351-361.

Zukoski E.E. (1966): Influence of viscosity, surface tension, and inclination angle on motion of long bubbles in closed tubes, Journal Fluid Mech. 20, 821-832.

Delano, A.D. (1998): Design analysis of the Einstein refrigeration cycle, Ph.D. dissertation, Georgia Institute of Technology.

Kouremenos D.A. and Staicos J. (1985): Performance of a small air lift pump, International journal of Heat and Fluid Flow, vol.6, no. 3, 217-222.

Clark N.N. and Dabolt R.J. (1986): A general design equation for airlift pumps operating in slug flow, AIChe journal 32(1), 56-64.

de Cachard F. and Delhaye J.M. (1996): "A slug-churn model for smalldiameter airlift pumps". Int. J. Multiphase Flow 22(4) : 627-649.

Lockhart R.W. and Martinelli R.C. (1949): Proposed correlation of data for isothermal two-phase component flow in pipes, Chem. Eng. Prog. 45, 3948.

Chisholm D. (1983): Two-phase flow in pipelines and heat exchangers,(Newyork: george Goodwin).

Collier J.G. and Thome J.R. (1996): Convective boiling and condensation, (Newyork Mcgraw-Hill Book co).

Hewitt G.F. and Roberts D.N. (1969): "Studies of two-phase flow patterns by simultaneous x-ray and flash photography". AERE-M 2159, HMSO. UKAEA Robert No. AERE-R 4022. HMSO, London.

Jayanti S. and Hewitt G.F. (1992): "Prediction of slug-tochurn flow transition in vertical two-phase flow". Int. J. Multiphase Flow 18(6) 847-860.

Stepanoff A.J. (1929): Thermodynamic theory of the air lift pump, ASME Transactions 51, 49-55.

Awari G. K., et al. (1998): Investigation on Airlift pump, Proc of International conference on Fluid Mechanics and Fluid power, (IIT, Delhi) Vol. 2, 869-875.

Awari G. K., Ardhapurkar P. M, Wakde D. G. (2004): An experimental analysis of two phase flow for air lift pump design, Proc Advances in Fluid Mechanics (ISBN: 1-85312-704-3,WIT press, Southampton, Boston, UK) , 267-276.

Theyyunni T.K. (1991): Application of fluid technology in nuclear chemical plants, Journal of engineering advances 61-66.

Parker G. J. (1980): The effect of foot piece design on performance of a small air lift pump, International journal of Heat and Fluid Flow, vol.2, no. 4 (1980) 245-252. 